\title{
Online course delivery, assessment, and student satisfaction: The case of Quantitative Chemical Analysis course in the time of COVID-19 pandemic
}

\author{
Ghassan Sonji $^{1}$ (D) Dalal Hammoudi Halat ${ }^{1}$ (D) Zeina Mehyou $^{1,2}$, Mohamad Rahal ${ }^{1}$ (D) \\ ${ }^{1}$ Pharmaceutical Sciences Department, School of Pharmacy, Lebanese International University, Lebanon \\ ${ }^{2}$ Biological and Chemical Sciences Department, School of Arts and Sciences, Lebanese International University, Lebanon
}

\section{Keywords}

Asynchronous learning

COVID-19 educational disturbance

Online assessment

Online learning environment

Student satisfaction

Synchronous learning

\section{Correspondence}

Ghassan Sonji

Pharmaceutical Sciences Department

School of Pharmacy

Lebanese International University

Lebanon

ghassan.sonji@liu.edu.lb

\begin{abstract}
Background: The COVID-19 pandemic has transformed the concept and perception of normalcy, compelling instructors to switch from face-to-face to online instruction overnight. Meanwhile, the satisfaction of course learning outcomes remains a critical element of modern educational systems and should be monitored during online education. Objective: The purpose of this study was to describe the online delivery and assessment tools of a Quantitative Chemical Analysis course and evaluate student satisfaction. Methods: Formative and summative assessments were used to test students' learning and the application of Quantitative Chemical Analysis concepts using online teaching models. At the end of the semester, a Likert scale survey was sent to all students to get their feedback. Results: Students were extremely satisfied with online learning, believing that the course's intended learning outcomes were met, with student ability to perform calculations and evaluate errors, precision, and accuracy receiving the highest scores, and student ability to explore multiple solutions for a given problem receiving the lowest scores.
\end{abstract}

\section{Introduction}

The quality of teaching and learning has been one of the most pressing concerns in Lebanese university education (Nauffal, 2009). One of the primary aims of higher education is for students to learn skills and achieve high levels of cognitive ability, guided and directed by the instructor's expertise (Medina et al., 2017). Content knowledge (knowledge of the subject), pedagogical content knowledge (knowledge about teaching and learning a specific subject), and general pedagogical knowledge (knowledge about teaching and learning that is not related to subject matter) are the three components of instructor's knowledge that are commonly differentiated (Kleickmann et al., 2013). Innovative teaching is a proactive technique of incorporating advanced teaching ideas and methodologies into a classroom. Adopting creative approaches in institutions has the potential not only to improve education but also to empower people, strengthen governance, and galvanise the effort to accomplish the country's human development objective (Hailemeskel et al., 2018).

Education goals should be defined in terms of topic content as well as intellectual skills, procedures, and tactics. There are five broad objectives that students should acquire: a high level of knowledge in the subject area; cognitive and metacognitive skills and strategies that they can use as they engage in various cognitive processes; ability to use these skills and strategies independently and take responsibility for their own learning; awareness of the nature of thinking and ability to control their attitudes, dispositions, and development; standards for evaluating what constitutes "good" thinking and ability to think critically and creatively (Martirosov \& Moser, 2021).

Conventional teaching, or the delivery of science and training using traditional techniques, is described as the utilisation of lecture and laboratory sessions. Class sessions between instructors and students are 
organised such that the instructor imparts subject information to the learner, and the learner uses supplemental aids such as textbooks to reinforce what the instructor had taught. This idea was popular not only in pharmacy classes but also in other majors; moreover, stand-and-deliver instruction was the norm in most areas of education (Jin et al., 2021).

Nevertheless, in higher education, distance learning has long been a notion. When a physical distance occurs between the student and the instructor, it refers to learning mediated through technological equipment. Distance learning technologies provide a wide range of options for educational content presentation, knowledge assessment, and performance monitoring, resulting in a full-fledged educational process. The rise in online course delivery dates back to the 1990s when it became clear that technology would have a transformative influence on higher education (Lean et al., 2020). Simultaneously, alternative distant education modules have emerged, such as blended (or hybrid) learning, which describes a combination of face-to-face and technology-mediated instructions and provides a robust, accessible learning experience (Balakrishnan et al., 2021).

Course evaluation and assessment is a standard part of the curriculum in today's educational systems (Bajis et al., 2018). Learning outcomes predate modern assessment and certification systems, and they emerge primarily from a long-running dispute about the optimal teaching technique for enhancing critical thinking and, as a result, learning. They are not a summary of a learning unit's content or syllabus (course, module, or even programme and degree). They are also not what the faculty wants to accomplish or communicate, and they should not be confused with, or mistaken for, learning objectives, which are equally important components of a learning unit. The information to be integrated into the learning process, as well as the generic skills, knowledge, and understanding that the student must accomplish and possess by the end of a learning unit, are laid out in clear terms in objectives. Learning outcomes, on the other hand, are rather more concerned with the learner and highlight the cognitive and experiential skills required to meet the learning objectives. Both faculty and students benefit from learning outcomes because they are educational and learning-related. In addition, it is in this area where the fascinating and participatory learning process occurs. Identifying learning outcomes, for example, is the cornerstone upon which the syllabus, content, objectives, assessment, and teaching style (methodology) for a learning unit are built (Hudgens \& Chirico, 2010; Yusuff, 2018; Pires \& Cavaco, 2019).
Due to the rising coronavirus pandemic, institutions all around the world have been compelled to cancel classes and close their doors in March 2020. Students were subject to confinement regulations in accordance with the government's precautions for their safety. As a result, students and educators had to quickly adjust to a new learning and teaching paradigm when face-toface sessions were halted and replaced with online activities. The shift to remote learning that occurred in spring 2020 as a result of the COVID-19 pandemic presented several challenges for students and educators (Dhawan, 2020; Altwaijry et al., 2021). Educators were worried and anxious, with the main concern being how to proceed with online teaching activities without risking student commitment and involvement. While weathering personal and professional turmoil, LIU pharmacy professors collaborated to share resources and explore ways to create a convenient learning environment for their students. Numerous papers concerning pharmacy remote learning techniques and resources have been published and assisted in creating a new pedagogical experience (Alqurshi, 2020; Higbea et al., 2020; Lyons et al., 2020). Following a new wave of coronavirus outbreaks in January 2021, the Lebanese government declared a third national lockdown, with new limitations impacting all levels of education, necessitating a new stage of emergency remote instruction. In light of the pandemic scenario and the ensuing suspension of face-to-face sessions, the instructors modified activities and instructional tools to encourage asynchronous projects that students could do on their own.

While students' languages and cultures may vary per country, their pharmacy courses are fairly similar. With few exceptions, undergraduate pharmacy students are expected to complete their degrees in five years by taking undergraduate coursework (Supapaan et al., 2019). Analytical chemistry methods are an important aspect of making decisions in pharmaceutical chemical research, and students must have a thorough understanding of them to undertake accurate analysis (Adams \& Adriaens, 2020). The pharmaceutical sciences department at the Lebanese International University (LIU) offers a two-credit course, didactic and practical, that would appeal to undergraduate pharmacy students. Students are introduced to the quantitative analytical chemistry course (PHAR205), which includes theory, exercises, presentations, practices and procedures, and reporting. This course is offered in the second year of the pharmacy programme. The related laboratory activities in the course consist of 10 weekly experiments, with 20 students per section, and primarily rely on course instructors with a solid analytical or pharmaceutical 
chemistry background, together with laboratory assistants. Students work in pairs, and each pair is in charge of analysing one analytical sample. Practical laboratory courses are essential because they allow students to apply what they have learned in class through active investigation and expand their mental understanding of the topic. If pharmacy students are asked to undertake their own research to address industrial problems after graduation, their ability to do so will be dependent on the foundation they gained in research methodologies, critical thinking skills, and quantitative procedures, all of which may be learned in a lab setting, with Quantitative Chemical Analysis course being a good example.

\section{Description of the area for the current paper Pedagogical guidelines}

Bloom's Taxonomy is a hierarchical model of thinking that categorises levels of thinking into six categories ranging from low, basic cognitive thinking to high, complex cognitive thinking. This model constitutes the best way to represent higher-order thinking. Knowledge, comprehension, application, analysis, synthesis and evaluation are the six cognitive stages, arranged from simple to complicated and which are hierarchically cumulative. Low-order, basic cognitive thinking levels include knowledge, understanding, and application. Before going on to higher-ordered cognitive thinking levels, lower-ordered cognitive thinking must be mastered. Higher-order, sophisticated cognitive thinking levels include analysis, synthesis, and assessment (Stupans, 2017).

Bloom's taxonomy was also structurally altered by Anderson and the authors (Ari, 2011), who added knowledge as a new dimension. Bloom's Cognitive Process Dimension defines the learning process and reflects the initial cognitive levels. The new Knowledge Dimension identifies the different types of knowledge that must be acquired (Table I). Traditional laboratory programmes frequently employ the two bottom levels of Bloom's Taxonomy, knowledge (recall of material) and understanding (ability to summarise and discuss). This might lead to students improperly performing in future occupations that need much more than merely memorising information and being able to summarise/discuss. Students must be able to use the four higher levels of Bloom's Taxonomy in order to be successful in school and in their careers. The quantitative Chemical Analysis curriculum allows students to learn the underlying concepts involved in the experiments, develop their critical thinking skills, and use those skills to examine problems as well as develop their own methods of analysis to be able to solve any chemistryrelated problems they may come across in the future.

Table I: Bloom's revised two-dimensional taxonomy table (Anderson, 2005)

\begin{tabular}{|c|c|c|c|c|c|c|c|}
\hline \multicolumn{8}{|c|}{ Cognitive process dimension } \\
\hline \multirow{5}{*}{ 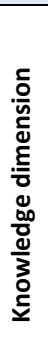 } & & Remember & Understand & Apply & Analyse & Evaluate & Create \\
\hline & Factual knowledge & List & Summarise & Classify & Order & Rank & Combine \\
\hline & $\begin{array}{l}\text { Conceptual } \\
\text { knowledge }\end{array}$ & Describe & Interpret & Experiment & Explain & Assess & Plan \\
\hline & $\begin{array}{l}\text { Procedural } \\
\text { knowledge }\end{array}$ & Tabulate & Predict & Calculate & Differentiate & Conclude & Compose \\
\hline & $\begin{array}{l}\text { Metacognitive } \\
\text { knowledge }\end{array}$ & Appropriately use & Execute & Construct & Achieve & Act & Actualise \\
\hline
\end{tabular}

\section{Assessment of student learning}

In the literature, assessment is commonly regarded as the core of the student experience and, most likely, the sole important impact on how they approach learning. It is the process through which instructors collect data in the classroom on how well students are meeting the targeted instructional objectives. It involves devising assessment methods, administering, scoring and interpreting exams, communicating assessment findings, developing grading systems, and making educational decisions. When the assessment possesses the following features, it has a good impact on learning and encourages students to fully participate: 1 ) it is linked to real-world activities; 2) it fosters the application of the information in practical situations; 3 ) it supports the development of diverse abilities; and 4) it has long-term and non-academic advantages (Darling-Hammond et al., 2020).

The instructor should utilise several metrics and authentic evaluations to determine if the students have the necessary abilities to function in society successfully. The use of these tools implies a higher chance of alignment with objectives and competencies, a lesser chance of cheating, and a higher chance of an actual evaluation of student competency and performance: using several assessment methods is just 
excellent teaching. Authentic assessment aligned with the teaching process offers proof of the learner's thinking level and curriculum knowledge and, as a result, directs learning. Authentic assessment should concentrate on cognitive processes essential in contexts other than the subject at hand and life outside of school, thereby simulating real-world task scenarios (Wiewiora \& Kowalkiewicz, 2019; Villarroel et al., 2021). Furthermore, because evaluation is such a relevant element of the educational process, it is also a sensitive issue. As a result, it is frequently the portion of the process that receives the most criticism, particularly true in online learning owing to the lack of face-to-face interactions that allow instructors to watch and assess learner behaviour.

In contrast to traditional face-to-face assessment, where the learner is often "treated as an isolated individual with limited access to resources and other people", learners in the e-learning environment have "almost limitless digital resources". Thus, in an online learning environment, assessment methods must employ various measures of learner performance that are explicit, coherent with the learning objectives, aligned with the subject content taught and the kind of instruction, and genuine. The instructor and the students must both be dedicated to the learning goals for assessment to be successful. It is also critical that the assessment tools and techniques guarantee that the teaching/learning process is feasible and fair and that the assessment is administered adequately (Burns, 2011; Foo et al., 2021).

One strategy to circumvent the limitations of online assessment is for learners to be examined continually and formatively by a variety of assessment tools, such as self-evaluation (essential in more constructive approaches); collaborative assessment or peerassessment; rubrics; quantitative and qualitative involvement utilising synchronous and asynchronous communication and collaboration tools accessible on online platforms, such as chat rooms, e-mail, discussion forums, and wikis; quizzes and exams; or even the creation of an e-portfolio (Ayub et al., 2021). Quantitative chemical analysis course students benefited greatly from the use of rubrics, margin comments, and discussion boards, all of which were excellent techniques for providing feedback. As a result of this input from students, instructors were prepared to make changes to the course to fit online delivery.

\section{Assessment types}

Assessment for Learning (AfL), also known as formative assessment or the pedagogical pole, is a continuous evaluation that aims to enhance individual student performance, student learning outcomes at the course or programme level, or overall institutional effectiveness. This assessment, in theory, enables a professor, professional staff member, or programme director to respond rapidly to modify the contents or approach of a course or programme. For example, rather than just proceeding with the course's predetermined topics, faculty members may change their next unit after assessing student performance on an assessment at the end of the first unit. Many instructors also request brief assessments of their teaching on a regular basis, and the information gathered from these may be utilised to make changes that may increase learning, such as including more discussion in a class.

Assessment of Learning (AoL), also known as summative assessment or the societal pole, on the other hand, takes place after the conclusion of a unit, course, or programme. This assessment is used to see if the general objectives have been met and to get information on individual student performance or statistics about a course or programme for internal or external accountability purposes. The most common type of summative evaluation is a grade. After faculty members describe what they anticipate students to be able to accomplish or what abilities they expect students to attain when they complete a course, programme, or graduate from the institution, goals for student learning will be evaluated and communicated in a summative manner.

Formative and summative assessments complement one another to promote learning. They should be influential components of the evaluation at the course and, if applicable, programme levels (Bacquet, 2020).

\section{Course description}

Target group

The Quantitative Chemical Analysis is a major course for second-year undergraduate students offered in the spring and the summer terms at LIU school of pharmacy.

\section{Course goals}

The course is intended to help students identify the analytical terms and expressions used in analytical methods, describe the principles of experimental errors in chemical analysis, including the sources of experimental errors and the application of statistics to data treatment and evaluation, define and apply techniques of volumetric, gravimetric, complex formation and oxidation/reduction titrations, and define and apply techniques of electroanalytical and spectroscopic analysis. 


\section{Course content}

This course covers the main analytical concepts and issues, such as acid-base titrations, complexometric titrations, redox titrations, buffer solutions and $\mathrm{pH}$ measurement, and electrochemistry.

\section{Delivery mode}

During the spring term 2020-2021, the Quantitative Chemical Analysis course was delivered online, using Google Classroom as the principal interaction platform. All students had access to Google Classroom through their personal university accounts, where a personal Gmail and Google Workspace were available (Hallal et al., 2020; Hammoudi Halat et al., 2020). The lessons, scheduled over ten weeks, lasted a total of two hours and thirty minutes each week. This time was divided among synchronous Zoom or Google Meet sessions (running for 60 to 90 minutes) and asynchronous sessions (lasting approximately 60 minutes). The instructor posted a study guide on Google Classroom stream at the start of each week to help students manage their time and arrange their work.

During the asynchronous period of the class, students watched pre-recorded lecture videos discussing the theory behind the experiment, deepening the knowledge and analytical skills of the concepts involved in the specific experiment. These videos were also intended to introduce equipment, discuss the aims of each experiment, and demonstrate any distinctive approaches used during the experimental execution. After watching those videos, students were quite ready to acquire more challenging skills and further discuss and synthesise any possible experimental findings following the synchronous lectures.

Then, the instructor employed explanatory and demonstrative lectures in the synchronous sessions, relying on commented resources (such as PowerPoint slides) and solving tasks on a whiteboard. Formative exercises were developed to allow students to examine their understanding and comprehension of the material presented in pre- and post-synchronous lectures. A video conferencing platform was required to allow participants to discuss, and this was aided by technology allowing the lecturer to write and draw in real-time. Instructors had the freedom to choose the convenient software and hardware to optimise their lectures and deliver in the most interactive and explicit scenario. Each lecture in the Quantitative Chemical Analysis course began with a "Challenge," which consisted of a challenging topic that demanded a review of material covered in the previous lecture. After completing the problem individually or in a group of students, the following issue in the topic module was discussed. Student participation was an important aspect of online lectures. During lectures, instructors would poll the students, and the answers were then utilised to guide the conversation and clear up any misconceptions. The instructors also attempted to involve students by incorporating their suggestions and making frequent use of polling and chat capabilities. Synchronous lectures were systematically recorded for excused students to watch at their convenience.

At the end of each synchronous session, these activities were completed asynchronously, either individually or in groups. During the asynchronous period of the class, students could watch videotaped demonstrations of experiments filmed by lab instructors or assistants. The asynchronous component included recordings that students could watch at their convenience. The recordings included instructor 1 ) lectures to explain topics, 2) films that illustrate experiments, and 3) podcasts that show how instruments and devices were used. It also included extra readings and challenges to augment synchronous lectures and enhance their effectiveness. A platform that tracks download statistics can be beneficial when assessing the reach and possible implications of uploaded content. A typical film lasted around 20 minutes and contained views of balance display and glassware scales, allowing students to get data straight from the equipment used in the lab in simulated mode. Asynchronous learning activities benefitted students who shared devices, living spaces, and the Internet with others or those who had unanticipated obligations owing to the pandemic. It has been established that multimedia movies can be a highly effective teaching tool for delivering content to students if cognitive load, student engagement, and active learning have been all considered when creating videos (Sung et al., 2021).

In general, Quantitative Chemical Analysis course instructors focused on learning goals that did not need in-person experiments in reaction to the worldwide pandemic. Students were expected to (i) use statistical analysis methods to organise, analyse, and evaluate experimental datasets, (ii) use fundamental theories to explain experimental phenomena, (iii) examine and understand laboratory safety protocols, and (iv) assess laboratory processes using the information gained in the lecture on chemical analysis fundamentals.

\section{Instructional materials}

Course materials were made available online in the form of PowerPoint presentations, Word or PDF files, and links to external resources from the Internet. Lecture videos and laboratory demonstration videos were uploaded on the Google Classroom stream for students to view at their own pace. 


\section{Student assessment}

It was necessary to make sure that online evaluations were aligned with the course's didactic framework. As such, students were required to accomplish the following tasks in order to pass the course:

- Complete at least three assignments (formative assessment) during the course and submit them to the instructor (by e-mail or through Google Classroom) on time. Assignments consisted of multiple-choice questions meant to highlight the key themes of a chapter and help students recognise course concepts in a new, different context.

- Take two short tests (15-minute online quizzes, formative assessment) at the end of some stages, as well as a 60-minute online midterm in the seventh week and a final exam in the final week (summative assessment), to cover the material (course, laboratory, and theoretical-practical discussions). Exams consisted of multiple-choice, matching, and fill-in-the-blank questions. As soon as the time restriction ran out, students were penalised for submitting their work late.

- Timely submit experimental reports. The lab report was written by groups of two students and submitted using Google Classroom within one week of each session. Quantitative data collection, contrasting collected experimental findings, and presenting conclusions were among the performance markers.

Moreover, a laboratory evaluation grade in the Quantitative Chemical Analysis course was classically based on technical and manipulative skills in using laboratory equipment, tools, materials, and computer software and understanding laboratory procedures, including health and safety and scientific methods. For online instruction, this evaluation included the complementary skills of collaborative learning and teamwork, as well as understanding and preparing for possible future roles in laboratory-based settings.

The overall assessment of a student in the Quantitative Chemical Analysis course was a composite of the grades of the midterm exam (30\%), final exam (35\%), reports (20\%), quizzes, assignments, and evaluations (all amounting to $15 \%$ ). When given comparable learning experiences, online and classroom-based learners are expected to achieve equivalent learning outcomes. The Quantitative Chemical Analysis online course was completed successfully by all of the students who were enrolled, suggesting that the online and resource components had no negative impact on learning. No other conclusions could be reached because of the small number of students in each class. Figure 1 depicts how remote learning approaches were implemented using synchronous and asynchronous technologies for introduction, training, evaluation, and feedback in the Quantitative Chemical Analysis course. There are 4 steps: (1) course presentation with modes of delivery; (2) engagement and activities of students; (3) formative and summative assessments; (4) getting feedback. Follow-up of course progress throughout the term was routinely done, and methods of teaching and assessment were checked among different sections to ensure consistency.

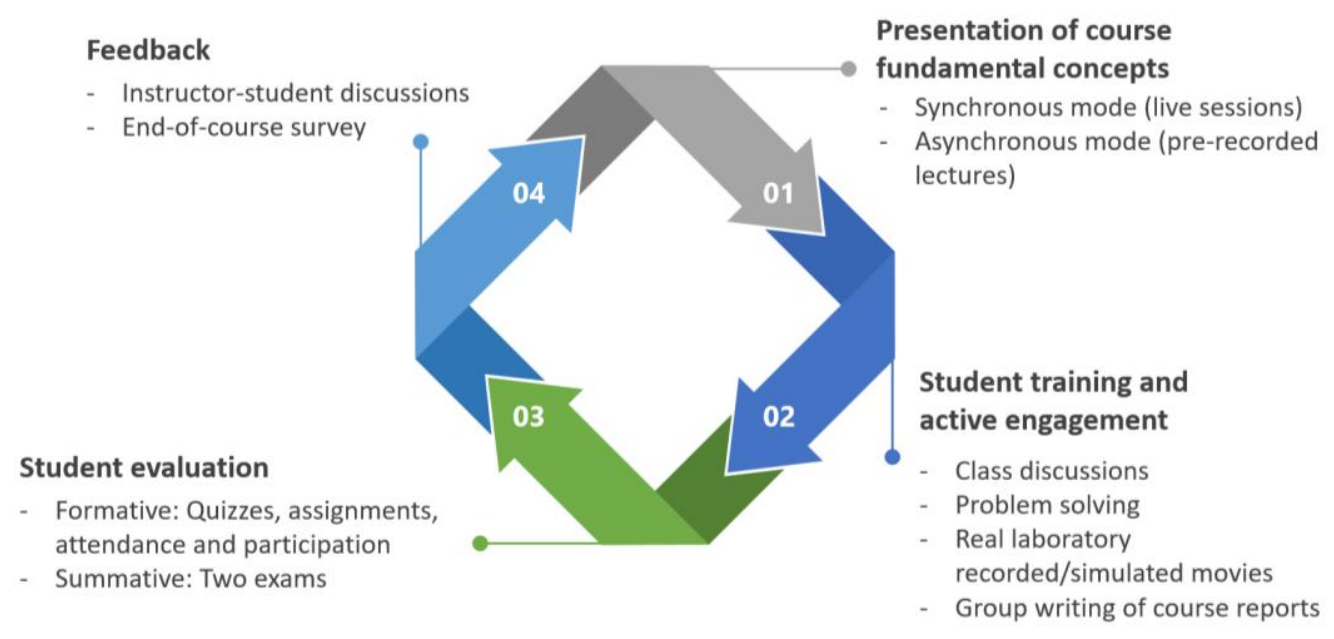

Figure 1: Summary of course flow in the Quantitative Chemical Analysis course 


\section{Evaluation}

\section{Statement of the problem}

In higher education, a growing trend to move away from the traditional synchronous classroom model in favour of one that relies heavily on technology is taking place. Despite several studies showing that online teaching is as effective as traditional face-to-face teaching techniques, some studies report that educators and non-educators alike are sceptical about the effectiveness of online education. Students who embrace and understand the impact of technology may have a better readiness and capacity to achieve their educational goals. Significant differences in student success between online and face-to-face environments remain unclear since prior research has shown inconsistent results (Curley et al., 2018; Coman et al., 2020).

\section{Purpose of the study}

Bromley (Maree, 2007) defines a case study as "a systematic inquiry into an event or a set of related events, which aims to describe and explain the phenomenon of interest". Simons (2009) elaborates on this concept by stating that "a case study is an in-depth exploration from multiple perspectives of the complexity and uniqueness of a particular project, policy, or programme in a 'real-life' context". The following are the key goals of a case study, according to this author:

- Generation of information.

- Development of a thorough understanding of a particular issue, policy, etc.

- Assisting in the development of policy, professional practice, and community action.

The Quantitative Chemical Analysis online course was offered in the spring term 2020-2021. The goal of this case study was to explore student satisfaction about the course delivery and assessment tools using an endof-course survey. The latter aimed to verify the extent to which the methods utilised in the e-learning pedagogy were practical, valid, and trustworthy.

\section{Study sample}

The target population for this study was undergraduate students who enrolled in the Quantitative Chemical Analysis online course offered during the spring term 2020-2021. The population included 34 students who were enrolled in the course remotely and were divided into two sections, each taught by a different instructor. Because statistical tests usually require a larger sample size to ensure a representative distribution of the population, studies with a small number of participants have been demonstrated to produce statistical conclusions that are less generalisable to other groups. All students in both sections had undergone the same assignments and examinations.

\section{Student survey (end-of-course assessment)}

At the end of the semester, students completed a voluntary, anonymous online survey posted on the Google Classroom stream after final exams. Students rated eight statements about their satisfaction with the course and the fulfilment of course learning outcomes using a 5-point Likert scale from 1 (strongly disagree) to 5 (strongly agree). These statements were based on the intended learning outcomes as spelt out in the course syllabus. Data from the survey responses were quantitatively analysed to evaluate respondent agreement or disagreement with the selected statements.

\section{Results and discussion}

Table II shows mean scores and standard deviation of student responses to the eight learning outcomes. These means ranged between 4 and 4.6, indicating that students believed that the intended learning outcomes were satisfactorily achieved. The highest evaluations were for student ability to perform calculations (mean $=4.6 / 5$ ) and evaluate errors/accuracy/precision (mean=4.3/5). The lowest evaluations were for student ability to explore multiple solutions for a given problem (mean=4/5).

Overall, the students were satisfied with the course, as shown in their responses. Given that all enrolled students passed, it may be inferred that achievement of learning outcomes of the course measured by summative evaluations (instructor's perspective) was in line with satisfaction measured by the survey (students' perspective). Item 1 in the survey shows that students were satisfied with the level of understanding of the analytical techniques taught, a cornerstone in the Quantitative Chemical Analysis course. It was anticipated that efforts of the instructors to explain such principles in live meetings and asynchronous material and their use of recorded/simulated videos led to such a result. In our previous research on pharmacy laboratory courses delivered remotely, students had expressed their satisfaction with simulated videos but preferred those recorded by instructors (Halat et al., 2020). With the Quantitative Chemical Analysis course having an important laboratory component, the use of videos to illustrate experiments has contributed to student learning and fulfilled a key outcome of the course. 
Table II: Likert scale survey results for end-of-course assessment

\begin{tabular}{|c|c|c|c|c|c|c|c|}
\hline PHAR205 Learning outcomes & $\begin{array}{c}1 \\
\text { Strongly } \\
\text { Disagree }\end{array}$ & $\begin{array}{c}2 \\
\text { Disagree }\end{array}$ & $\begin{array}{c}3 \\
\text { Neutral }\end{array}$ & $\begin{array}{c}4 \\
\text { Agree }\end{array}$ & $\begin{array}{l}5 \\
\text { Strongly } \\
\text { Agree }\end{array}$ & Mean & SD \\
\hline $\begin{array}{l}\text { 1. The course allowed me to describe the basic } \\
\text { principles and the apparatus of a variety of analytical } \\
\text { techniques used in quantitative chemical analysis. }\end{array}$ & $\begin{array}{c}1 \\
(2.9 \%)\end{array}$ & $\begin{array}{c}0 \\
(0 \%)\end{array}$ & $\begin{array}{c}4 \\
(11.8 \%)\end{array}$ & $\begin{array}{c}15 \\
(44.1 \%)\end{array}$ & $\begin{array}{c}14 \\
(41.2 \%)\end{array}$ & 4.2 & 0.88 \\
\hline $\begin{array}{l}\text { 2. The course allowed me to perform calculations to } \\
\text { determine the concentration of analyzed solutions, } \\
\text { and calculate the relative percent error based on the } \\
\text { labeled amount. }\end{array}$ & $\begin{array}{c}0 \\
(0 \%)\end{array}$ & $\begin{array}{c}1 \\
(2.9 \%)\end{array}$ & $\begin{array}{c}2 \\
(5.9 \%)\end{array}$ & $\begin{array}{c}7 \\
(20.6 \%)\end{array}$ & $\begin{array}{c}24 \\
(70.6 \%)\end{array}$ & 4.6 & 0.74 \\
\hline $\begin{array}{l}\text { 3. The course allowed me to apply quantitative } \\
\text { chemical analysis in quality control to ensure that } \\
\text { the highest quality standards were met. }\end{array}$ & $\begin{array}{c}0 \\
(0 \%)\end{array}$ & $\begin{array}{c}1 \\
(2.9 \%)\end{array}$ & $\begin{array}{c}6 \\
(17.6 \%)\end{array}$ & $\begin{array}{c}13 \\
(38.2 \%)\end{array}$ & $\begin{array}{c}14 \\
(41.2 \%)\end{array}$ & 4.2 & 0.83 \\
\hline $\begin{array}{l}\text { 4. The course allowed me to apply experiments of } \\
\text { titrimetric techniques and spectrophotometric } \\
\text { analysis of single and multi-component samples. }\end{array}$ & $\begin{array}{c}1 \\
(2.9 \%)\end{array}$ & $\begin{array}{c}0 \\
(0 \%)\end{array}$ & $\begin{array}{c}8 \\
(23.5 \%)\end{array}$ & $\begin{array}{c}8 \\
(23.5 \%)\end{array}$ & $\begin{array}{c}17 \\
(50 \%)\end{array}$ & 4.2 & 1 \\
\hline $\begin{array}{l}\text { 5. The course allowed me to identify the primary } \\
\text { problem in analysis while defining goals and } \\
\text { alternative ones. }\end{array}$ & $\begin{array}{c}0 \\
(0 \%)\end{array}$ & $\begin{array}{c}1 \\
(2.9 \%)\end{array}$ & $\begin{array}{c}7 \\
(20.6 \%)\end{array}$ & $\begin{array}{c}10 \\
(29.4 \%)\end{array}$ & $\begin{array}{c}16 \\
(47.1 \%)\end{array}$ & 4.2 & 0.88 \\
\hline $\begin{array}{l}\text { 6. The course allowed me to explore multiple } \\
\text { solutions by developing potential strategies to solve } \\
\text { identified problems. }\end{array}$ & $\begin{array}{c}0 \\
(0 \%)\end{array}$ & $\begin{array}{c}1 \\
(2.9 \%)\end{array}$ & $\begin{array}{c}9 \\
(26.5 \%)\end{array}$ & $\begin{array}{c}12 \\
(35.3 \%)\end{array}$ & $\begin{array}{c}12 \\
(35.3 \%)\end{array}$ & 4 & 0.87 \\
\hline $\begin{array}{l}\text { 7. The course allowed me to identify and evaluate } \\
\text { sources of error in an experiment and how to assess } \\
\text { the accuracy and precision of measurements when } \\
\text { collecting data or reporting results. }\end{array}$ & $\begin{array}{c}0 \\
(0 \%)\end{array}$ & $\begin{array}{c}3 \\
(8.8 \%)\end{array}$ & $\begin{array}{c}2 \\
(5.9 \%)\end{array}$ & $\begin{array}{c}11 \\
(32.4 \%)\end{array}$ & $\begin{array}{c}18 \\
(52.9 \%)\end{array}$ & 4.3 & 0.94 \\
\hline $\begin{array}{l}\text { 8. The course allowed me to employ the most } \\
\text { feasible solutions based on the acquired analytical } \\
\text { skills. }\end{array}$ & $\begin{array}{c}0 \\
(0 \%)\end{array}$ & $\begin{array}{c}2 \\
(5.9 \%)\end{array}$ & $\begin{array}{c}6 \\
(17.6 \%)\end{array}$ & $\begin{array}{c}12 \\
(35.3 \%)\end{array}$ & $\begin{array}{c}14 \\
(41.2 \%)\end{array}$ & 4.1 & 0.91 \\
\hline
\end{tabular}

SD: Standard Deviation; Results are presented as number and percentage of responses, and mean and standard deviation of the study population upon evaluation of course learning outcomes in both PHAR205 sections are shown.

The highest means of achieved learning outcomes refer to activities requiring student efforts, such as pharmaceutical calculations (item 2) and error/accuracy/precision estimations (item 7), as shown by the data. This result highlights the need, in remote learning, to encourage student-directed approaches, where students are guided by the instructor but are also self-dependent to acquire skills that depend on training and practice. Other course outcomes described in items 3, 4, and 5 were also achieved satisfactorily.

A look at items 6 and 8 shows that students' ability to explore multiple problem-solving strategies or pick the most convenient analytical method was less fulfilled than other items. It is not possible to conclude from these results whether the ability to think in many formats or select preferred solutions to a given problem has not been accomplished in this distance learning course. Further investigation is warranted to elucidate whether the achieved score was related to the nature of the course delivery (online) or if more maturity in using those skills is required for the student to be capable of solving such exercises. Such maturity would be acquired in more advanced courses like Pharmaceutical Analysis \& Biotechnology (for which
Quantitative Chemical Analysis is a pre-requisite), where students are introduced to the concepts of various modern instrumental analytical techniques used in pharmaceutical research and industry, with more spectroscopic, conductimetric, electrochemical, and separation techniques being covered. Thereafter, the higher exposure to chemical and physical laws, mathematical treatment of results, the better understanding of advantages and limitations, and the applications of each method would enable the learner to make wiser decisions in selecting the convenient analytical technique for routine or research analysis in the pharmaceutical field. Finally, it will be tempting to explore whether higher engagement of the students in the Quantitative Chemical Analysis course and more interaction with their instructors can improve such abilities.

A crucial decision made by an educator is how to assess student understanding. This study presents quantitative learning assessment procedures with a focus on remote course delivery. This case study attempted to explore the extent to which learners in the Quantitative Chemical Analysis course, delivered remotely during the spring term 2020-2021, were satisfied and that online learning was genuine, valid, 
and productive. These impressions were assessed through a student survey, where respondents provided graded responses to specific statements concerning targeted learning outcomes, allowing for quantitative data analysis.

This study presents some limitations. First, the end-ofcourse survey was based on the course syllabus and was kept as short as possible to encourage students to respond. However, a more detailed survey, including an assessment of the platform of teaching, difficulties and challenges faced, and what students believe can improve their learning process, will help discern the elements that play a prominent role in the achievement of our learning goals. Second, previous and future Quantitative Chemical Analysis courses offered in the spring should be compared to have a better understanding of course evaluation results. Third, the number of participants was limited and based on convenience sampling. A larger sample of students enrolled in the course from different backgrounds and academic levels would have been more representative and would have reflected more realistic student levels of satisfaction. Consequently, more research is needed to see if these findings can be applied to undergraduate students in other courses.

\section{Conclusion and recommendations}

The use of the Internet presents several challenges in distance learning, and some concerns need to be resolved for online education to be effective. Online courses have the potential to overcome the shortcomings of the past and give the student an adequate interactive experience that leads to a better learning environment in some cases. Students enrolled in the pharmacy programme in the spring term of 20202021 showed satisfaction with the online learning environment of the Quantitative Chemical Analysis course in this case study. Some of the reasons may include the support of instructors (e.g., one-on-one feedback, inclusion in learning, understanding of specific circumstances), the course multimodal online delivery (e.g., audio, video, texts, PowerPoint presentations), the course level of engagement (e.g., active classroom vs lecture-based), and instructors guidance and follow-up.

In terms of assessments, the multiple and various evaluations (formative, summative, timed synchronous exams, asynchronous assignments, reports, and exercises) employed in the Quantitative Chemical Analysis course indicate that scores achieved by students reflected, to a large extent, their level of thinking, and how far were tackled the most complex dimensions in Bloom's taxonomy and more. It also enabled students to examine their own understanding of the course content and goals before and after main exams.

As technology continues to profoundly affect education, and as remote instruction may significantly flourish based on the COVID-19 experience, additional methods can be utilised in courses similar to the Quantitative Chemical Analysis course to further enhance the learning experience. For instance, the use of Information Communication Technology allows computer simulations and helps students learn about some experimental procedures, familiarise with a method before real lab experience, or, in some circumstances, even substitute laboratory work if safety concerns prevent it (Blackburn et al., 2019; Wästberg et al., 2019). Self-paced virtual experiments (SPVEs) are asynchronous experience practices carried out in a virtual environment. This resource allows for an experimental learning environment even in the absence of tangible reagents or instruments; it is accessible at any time and from any location with minimal educational interaction. Several studies have shown that SPVEs help students understand complex topics and develop self-efficacy in scientific research (Morales-Cruz et al., 2021). The different methods remain updated, and instructors should stay abreast of these updates to enrich the learner experience.

\section{Ethical considerations}

Ethical clearance of this study was obtained from the LIU SOP research committee (2020RC-052-LIUSOP).

\section{Conflict of interest}

The authors declare no conflict of interest.

\section{Source of funding}

The authors did not receive any funding.

\section{References}

Adams, F., \& Adriaens, M. (2020). The metamorphosis of analytical chemistry. Analytical and Bioanalytical Chemistry, 412, 3525-3537. https://doi.org/10.1007/s00216-01902313-z 
Alqurshi, A. (2020). Investigating the impact of COVID-19 lockdown on pharmaceutical education in Saudi Arabia - A call for a remote teaching contingency strategy. Saudi Pharmaceutical Journal, 28(9), 1075-1083. https://doi.org/10.1016/j.jsps.2020.07.008

Altwaijry, N., Ibrahim, A., Binsuwaidan, R., Alnajjar, L., Alsfouk, B. A., \& Almutairi, R. (2021). Distance Education During COVID-19 Pandemic: A College of Pharmacy Experience. Risk Management and Healthcare Policy, 1(14), 2099-2110. https://doi.org/10.2147/RMHP.S308998

Anderson, L. W. (2005). Objectives, evaluation, and the improvement of education. Studies in Educational Evaluation, 31(2-3), 102-113.

https://doi.org/10.1016/j.stueduc.2005.05.004

Ari, A. (2011). Finding Acceptance of Bloom's Revised Cognitive Taxonomy on the International Stage and in Turkey. Educational Sciences: Theory \& Practice, 11(2), 767772.

Ayub, E., Mohamad, S. N. A., Wei, G. W., \& Luaran, J. E. (2021). Developing a Course for Learning at Scale in Moodle: A Design-Case Based on Learner's Experience at a Private University in Malaysia. International Journal of Information and Education Technology, 11(7), 303-312.

https://doi.org/10.18178/ijiet.2021.11.7.1527

Bacquet, J. N. (2020). Implications of Summative and Formative Assessment in Japan - A Review of the Current Literature. International Journal of Education \& Literacy Studies, 8(2), 28-35.

http://dx.doi.org/10.7575/aiac.ijels.v.8n.2p.28

Bajis, D., Moles, R., Hosp, D., \& Chaar, B. (2018). Stakeholders' Perspectives on Quality Assurance of Pharmacy Education in the Eastern Mediterranean Region. American Journal of Pharmaceutical Education, 82(10), 1209-1223. https://doi.org/10.5688/ajpe6482

Balakrishnan, A., Puthean, S., Satheesh, G., Unnikrishnan, M. K., Rashid, M., Nair, S., \& Thunga, G. (2021). Effectiveness of blended learning in pharmacy education: A systematic review and metaanalysis. PLOS ONE, 16(6), 1-17. https://doi.org/10.1371/journal.pone.0252461

Blackburn, R. A. R., Villa-Marcos, B., \& Williams, D. P. (2019). Preparing Students for Practical Sessions Using Laboratory Simulation Software. Journal of Chemical Education, 96(1), 153-158. https://doi.org/10.1021/acs.jchemed.8b00549

Burns, M. (2011). Distance Education for Teacher Training: Modes, Models and Methods. Education Development Center.

https://www.edc.org/sites/default/files/uploads/DistanceEducation-Teacher-Training.pdf

Coman, C., Țîru, L. G., Meseșan-Schmitz, L., Stanciu, C., \& Bularca, M. C. (2020). Online Teaching and Learning in Higher Education during the Coronavirus Pandemic: Students' Perspective. Sustainability, 12(24), 10367-10390. https://doi.org/10.3390/su122410367

Curley, L. E., Wu, Z., \& Svirskis, D. (2018). Using Technology in Pharmacy Education: Pharmacy Student Performance and Perspectives When Visual Aids Are Integrated into Learning. Frontiers in Pharmacology, 9, 1062-1070.

https://doi.org/10.3389/fphar.2018.01062
Darling-Hammond, L., Flook, L., Cook-Harvey, C., Barron, B., \& Osher, D. (2020). Implications for educational practice of the science of learning and development. Applied Developmental Science, 24(2), 97-140. https://doi.org/10.1080/10888691.2018.1537791

Dhawan, S. (2020). Online Learning: A Panacea in the Time of COVID-19 Crisis. Journal of Educational Technology Systems, 49(1), 5-22.

https://doi.org/10.1177/0047239520934018

Foo CC, Cheung B, \& Chu KM. (2021). A comparative study regarding distance learning and the conventional face-toface approach conducted problem-based learning tutorial during the COVID-19 pandemic. BMC Medical Education, 21(1), 141-146. https://doi.org/10.1186/s12909-02102575-1

Hailemeskel, B., Bisrat, A., Weaver, S., Marcus, M., \& Hawthoine, S. (2018). Development of a New Innovative Teaching Method Using a Comprehensive Approach: A Survey of Students' Opinion. Biomedical Journal of Scientific \& Technical Research, 3(4), 3494-3499.

https://doi.org/10.26717/BJSTR.2018.03.000943

Halat, D. H., Cherfan, M., Mourad, N., \& Rahal, M. (2020). Highlights from a model for remote delivery of pharmacy laboratory courses: Design, implementation and student feedback: Innovation in learning assessment. Pharmacy Education, 20(2), 49-51.

https://doi.org/10.46542/pe.2020.202.4951

Hallal, K., HajjHussein, H., \& Tlais, S. (2020). A Quick Shift from Classroom to Google Classroom: SWOT Analysis. Journal of Chemical Education, 97(9), 2806-2809. https://doi.org/10.1021/acs.jchemed.0c00624

Hammoudi Halat, H. H., Dalal, Marwan, A., Fatima, H., Hassan, H., Rawad, K., Ehsan, S.-A., Lama, S., \& Ahmad, F. (2020). Insights into the Positive Role of a Higher Education Institution in the Prevention of Misinformation During Pandemics: The Health Committee Model During COVID-19. Coronaviruses, 2(1), 11-17.

http://dx.doi.org/10.2174/2666796701999200915145332

Higbea, A., Bald, E., Isaacs, A. N., Richter, S. K., Stamm, P. L., \& Kassel, L. E. (2020). Forging ahead from adaptations of teaching during the COVID-19 pandemic: Perspectives from multiple pharmacy programs. Adapting pharmacy experiential education during COVID-19: Innovating remote preceptor resources, tools, and patient care delivery beyond virtual meetings. Journal of the American College of Clinical Pharmacy, 4(1), 101-112.

https://doi.org/10.1002/jac5.1349

Hudgens, J. R., \& Chirico, M. J. (2010). A Course Introducing the Principles of Pharmaceutical Care. American Journal of Pharmaceutical Education, 74(7), 131-138. https://doi.org/10.5688/aj7407131

Jin, Y. Q., Lin, C.-L., Zhao, Q., Yu, S.-W., \& Su, Y.-S. (2021). A Study on Traditional Teaching Method Transferring to ELearning Under the Covid-19 Pandemic: From Chinese Students' Perspectives. Frontiers in Psychology, 12, 1-14. https://doi.org/10.3389/fpsyg.2021.632787

Kleickmann, T., Richter, D., Kunter, M., Elsner, J., Besser, M., Krauss, S., \& Baumert, J. (2013). Teachers' Content 
Knowledge and Pedagogical Content Knowledge: The Role of Structural Differences in Teacher Education. Journal of Teacher Education, 64(1), 90-106. https://doi.org/10.1177/0022487112460398

Lean, Q. Y., Ming, L. C., Wong, Y. Y., Neoh, C. F., Farooqui, M., \& Muhsain, S. N. F. (2020). Online versus classroom learning in pharmacy education: Students' preference and readiness. Pharmacy Education, 20(1), 19-27

Lyons, K. M., Christopoulos, A., \& Brock, T. P. (2020). Sustainable Pharmacy Education in the Time of COVID-19. American Journal of Pharmaceutical Education, 84(6), 667672. https://doi.org/10.5688/ajpe8088

Maree, K. (2007). First steps in research (1st ed.). Pretoria: Van Schaik

Martirosov, A. L., \& Moser, L. R. (2021). Team-based Learning to Promote the Development of Metacognitive Awareness and Monitoring in Pharmacy Students. American Journal of Pharmaceutical Education, 85(2), 131-136. https://doi.org/10.5688/ajpe848112

Medina, M. S., Castleberry, A. N., \& Persky, A. M. (2017). Strategies for Improving Learner Metacognition in Health Professional Education. American Journal of Pharmaceutical Education, 81(4), 78-91. https://doi.org/10.5688/ajpe81478

Morales-Cruz, A. L., Ortiz-Andrade, B. M., Pilar-Albaladejo, J. D., Díaz-Vázquez, L. M., Rivera-González, U., \& López-Mejías, V. (2021). Remote pandemic teaching in quantitative and instrumental chemical analysis courses at a Hispanic serving institution. Analytical and Bioanalytical Chemistry, 413(11), 2845-2853. https://doi.org/10.1007/s00216-021-03243-5

Nauffal, D. I. (2009). Do educational outcomes in Lebanese universities differ based on the academic model? Education, Business and Society: Contemporary Middle Eastern Issues, 2(1), 6-19. https://doi.org/10.1108/17537980910938442

Pires, C., \& Cavaco, A. (2019). Scoping Pharmacy Students' Learning Outcomes: Where Do We Stand? Pharmacy (Basel), 7(1), 23-41.

https://doi.org/10.3390/pharmacy7010023

Simons, H. (2009). Case Study Research in Practice. London: SAGE

Stupans, I. (2017). A Curriculum Challenge-The Need for Outcome (Competence) Descriptors. Pharmacy (Basel), 5(1), 7-15. https://doi.org/10.3390/pharmacy5010007

Sung, S. H., Li, C., Huang, X., \& Xie, C. (2021). Enhancing distance learning of science-Impacts of remote labs 2.0 on students' behavioural and cognitive engagement. Journal of Computer Assisted Learning, 37(6), 1606-1621.

https://doi.org/10.1111/jcal.12600

Supapaan, T., Low, B. Y., Wongpoowarak, P., Moolasarn, S., \& Anderson., C. (2019). A transition from the BPharm to the PharmD degree in five selected countries. Pharmacy Practice, 17(3), 1611-1619.

https://doi.org/10.18549/PharmPract.2019.3.1611

Villarroel, V., Bruna, D., Brown, G. T. L., \& Bustos, C. (2021). Changing the Quality of Teachers' Written Tests by implementing an Authentic Assessment Teachers' Training
Program. International Journal of Instruction, 14(2), 9871000. https://doi.org/10.29333/iji.2021.14256a

Wästberg, B. S., Eriksson, T., Karlsson, G., Sunnerstam, M., Axelsson, M., \& Billger, M. (2019). Design considerations for virtual laboratories: A comparative study of two virtual laboratories for learning about gas solubility and colour appearance. Education and Information Technologies, 24(3), 2059-2080. https://doi.org/10.1007/s10639-018-09857-0

Wiewiora, A., \& Kowalkiewicz, A. (2019). The role of authentic assessment in developing authentic leadership identity and competencies. Assessment \& Evaluation in Higher Education, 44(3), 415-430.

https://doi.org/10.1080/02602938.2018.1516730

Yusuff, K. B. (2018). Does personalized goal setting and study planning improve academic performance and perception of learning experience in a developing setting? Journal of Taibah University Medical Sciences, 13(3), 232237. https://doi.org/10.1016/j.jtumed.2018.02.001 